\title{
Seletividade de Herbicidas para a Cultura de Milho (Zea mays) Aplicados em Diferentes Estádios Fenológicos da CULTURA ${ }^{1}$
}

\author{
Selectivity to Corn Crop (Zea mays) of Herbicides Applied in Different Crop Phenological Stages
}

\author{
LÓPEZ-OVEJERO, R.F. ${ }^{2}$, FANCELLI, A.L. ${ }^{3}$, DOURADO-NETO, D. ${ }^{3}$, GARCÍA y GARCÍA, A. ${ }^{2}$ e \\ CHRISTOFFOLETI, P.J. ${ }^{3}$
}

\begin{abstract}
RESUMO - O objetivo deste trabalho foi avaliar a seletividade de herbicidas aplicados em condições de pré e pós-emergência da cultura de milho, conduzida sob sistema de semeadura direta, sem a presença de plantas daninhas durante todo o ciclo da cultura. O híbrido utilizado foi o Pioneer 3027, e o delineamento experimental adotado foi em blocos casualizados, com 22 tratamentos e três repetições. Os tratamentos herbicidas utilizados (em g i.a. ha ${ }^{-1}$ ), com os respectivos estádios fenológicos (número de folhas definitivas $=\mathrm{NF}$ ) no momento da aplicação dos respectivos tratamentos herbicidas, foram: atrazine + metolachlor $(1.400+2.100)$ em condições de pré-emergência da cultura; (atrazine + metolachlor) + nicosulfuron $[(1.000+1.500+20)]$ com a cultura apresentando $\mathrm{NF}=2$; atrazine + óleo vegetal $(2.400+1.800), \mathrm{NF}=2,4$ e 8; atrazine + simazine $(1.250+1.250), \mathrm{NF}=2,4$ e 8 ; nicosulfuron $(40-\mathrm{NF}=2,4$ e $8 ; 20-\mathrm{NF}=4$ e 8 e $52-\mathrm{NF}$ $=4$ e 8); e (atrazine + óleo vegetal $)+$ nicosulfuron $[(800+600)+20 ;(800+600)+40$ e $(800+600)$ $+52), \mathrm{NF}=4$ e 8]. Foram feitas avaliações visuais de sintomas de fitotoxicidade provocados pelos herbicidas aos 7, 14 e 21 dias após aplicação, usando a escala proposta pela European Weed Research Council, além dos parâmetros relativos aos componentes de produção da cultura e produtividade final. Os resultados obtidos indicaram que a duração dos estádios fenológicos da cultura não foi afetada pelos herbicidas utilizados e que alguns tratamentos herbicidas, quando aplicados no estádio fenológico $2(\mathrm{NF}=8)$, reduzem o rendimento da cultura, devido à alteração do número de fileiras por espiga, do número de grãos por fileira e da massa de 1.000 grãos de milho, sendo recomendável a aplicação de herbicidas na cultura de milho até o estádio fenológico $1(\mathrm{NF}=4)$, para evitar danos à cultura por fitotoxicidade.
\end{abstract}

Palavras-chave: semeadura direta, fitotoxicidade, nicosulfuron.

\begin{abstract}
The objective of this research was to evaluate the selectivity of pre and post-emergence herbicides on corn crop under no-tillage system, kept weed-free throughout the crop cycle. The corn hybrid Pioneer 3027 was sown and the experimental design consisted of randomized blocks with 22 treatments and 3 replications. The following herbicide treatments (in $\mathrm{g}$ a.i. ha $\mathrm{a}^{-1}$ ) were applied in the respective phenological stages (number of definitive leaves $=N F)$ : atrazine + metolachlor $(1,400+$ $2,100)$ under pre-emergence conditions of the crop; (atrazine + metolachlor) + nicosulfuron $[(1,000+$ $1,500)+20]$ with the crop presenting $N F=2$; atrazine + vegetal oil $(2,400+1,800), N F=2,4$ and 8 , atrazine + simazine $(1,250+1,250), N F=2,4$ and 8 ; nicosulfuron $(40-N F=2,4$ and $8 ; 20-N F=$ 4 and 8 and $52-N F=4$ and 8); (atrazine + vegetal oil $)+$ nicosulfuron $[(800+600)+20 ;(800+$ $600)+40 e(800+600)+52), N F=4$ and 8 . Visual evaluations of the phytotoxicity symptoms were performed at 7, 14, and 21 days after each herbicide application, adopting the European Weed Research Council grading, besides parameters related to crop yield components and final yield. The results indicated that the herbicides did not affect the duration of the phenological stage of the crop. When sprayed at the phenological stage $2(\mathrm{NF}=8)$, some herbicides reduced crop yield due to the decrease in total number of corn grain rows per ear, total number of grains per row, and mass of 1,000 grains; being thus advisable to apply herbicides in the corn crop from seeding through the phenological stage $1(\mathrm{NF}=4)$, in order to avoid phytotoxicity to the corn crop.
\end{abstract}

Key words: no-tillage system, phytotoxicity, nicosulfuron.

Recebido para publicação em 11.2.2003 e na forma revisada em 12.12.2003.

Doutorando em Fitotecnia, Dep. de Produção Vegetal da Escola Superior de Agricultura "Luiz de Queiroz" - ESALQ/USP, Cx. Postal 9, 13418-900 Piracicaba-SP, Brasil, <rfloveje@ esalq.usp.br>; ${ }^{3}$ Professor. do Dep. de Produção Vegetal - ESALQ/USP. 


\section{INTRODUÇÃO}

O milho é uma das principais culturas da agricultura brasileira, não somente no aspecto quantitativo, como também no que diz respeito à sua importância estratégica, por ser a base da alimentação animal e, conseqüentemente, humana.

A redução do rendimento de produção da cultura, devido à competição estabelecida com as plantas daninhas, pode alcançar até $70 \%$ da sua produtividade potencial, variando em função da espécie e do grau de infestação das plantas daninhas, do tipo de solo, das condições climáticas reinantes no período, bem como do espaçamento, da variedade e do estádio fenológico da cultura e do período em que a convivência das plantas daninhas e da cultura acontece (Fancelli \& Dourado-Neto, 2000). Portanto, o controle de plantas daninhas é uma necessidade de ordem econômica; em razão da escassez e do conseqüente elevado custo da mão-de-obra, é necessária a utilização do método químico, mediante uso de herbicidas, o qual, devido à sua elevada eficiência, permite a execução dessa operação agrícola em tempo oportuno e de forma satisfatória.

Diversos são os herbicidas e/ou misturas recomendados para o controle de plantas daninhas na cultura de milho, sendo a maioria aplicada em condições de pré-emergência das plantas daninhas e da cultura (Silva \& Melhorança, 1991). Com o incremento da área de milho cultivada pelo sistema de semeadura direta, surgiu a necessidade do desenvolvimento de novos herbicidas recomendados em pós-emergência (Pinto et al., 1993; Silva \& Altoé, 1993; Ferreira et al., 1995). Para Christoffoleti \& Mendonça (2001), os programas de manejo de plantas daninhas na cultura de milho que utilizam herbicidas pós-emergentes têm aumentado bastante nos últimos anos. No entanto, o aumento de áreas aplicadas com herbicidas pós-emergentes leva a dois questionamentos importantes: o primeiro diz respeito à época de aplicação do herbicida em relação ao estádio fenológico da cultura, pois, se o momento de aplicação for inadequado, a produção da cultura pode ser reduzida pela injúria causada pelo herbicida na cultura; e o segundo refere-se ao estádio de desenvolvimento da planta daninha, devendo o herbicida ser aplicado com as plantas daninhas em estádio de maior suscetibilidade.

O rendimento de grãos da cultura de milho depende da população, da prolificidade, do número médio de fileiras de grãos por espiga, do número médio de grãos por fileira e da massa média por unidade de grão (ou semente). A população e a prolificidade devem ser otimizadas considerando-se a arquitetura da planta, as condições edafoclimáticas e a tecnologia empregada. O número de fileiras por espiga é definido quando a planta apresenta 8 a 12 folhas expandidas, aproximadamente um mês após a emergência, e o número médio de grãos por fileira é afetado pelo tamanho da espiga, a qual é definida a partir das 12 folhas até o florescimento da planta. A massa média por unidade de grão ou semente é marcadamente afetada a partir do estádio fenológico 6 , principalmente pela disponibilidade de água (Dourado-Neto \& Fancelli, 1997).

Assim, o herbicida a ser empregado deve ser preferencialmente seletivo para a cultura, não provocando injúrias nas plantas de milho, tanto na parte aérea quanto no sistema radicular, visto que inúmeras condições de uso podem causar distintos efeitos fitotóxicos. Por essa razão, é fundamental a avaliação, em condições de campo, da influência dos principais herbicidas aplicados em pré e pós-emergência sobre o desempenho da cultura de milho, independentemente da sua eficiência no controle de plantas daninhas. O presente trabalho teve por objetivo avaliar o efeito fitotóxico de herbicidas (recomendados para a cultura de milho), aplicados isoladamente ou em mistura e em diferentes dosagens, no desempenho da cultura de milho, em sistema de semeadura direta, avaliado pelas alterações fenológicas e pelos componentes do rendimento.

\section{MATERIAL E MÉTODOS}

O experimento foi conduzido no município

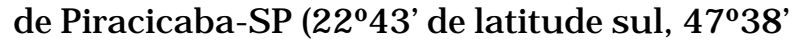
de longitude oeste e $580 \mathrm{~m}$ de altitude), na área experimental do Departamento de Produção Vegetal da Escola Superior de Agricultura "Luiz de Queiroz", Universidade de São Paulo, em solo classificado como Nitossolo vermelho (eutroférrico chernossólico) (EMBRAPA, 1999). O híbrido utilizado foi o Pioneer 3027 (híbrido 
triplo), de ciclo precoce e recomendado para semeadura em áreas a serem tratadas com o herbicida nicosulfuron. O milho foi semeado em 10 de novembro de 1998, em sistema de semeadura direta sobre palhada de milheto + aveia-preta. A dessecação da vegetação foi realizada no dia 22 de outubro de 1998, com o herbicida glyphosate na dose de $480 \mathrm{~g} \mathrm{~L}^{-1}(3,5 \mathrm{~L}$ de produto comercial ha-1). A semeadora utilizada foi a Semeato PAR 2000, de quatro linhas, regulada para a distribuição de 10 sementes $\mathrm{m}^{-1}$, no espaçamento de $0,85 \mathrm{~m}$. Na adubação de semeadura foram utilizados $30 \mathrm{~kg}$ de nitrogênio $(\mathrm{N}), 80 \mathrm{~kg}$ de fósforo $\left(\mathrm{P}_{2} \mathrm{O}_{5}\right)$ e $50 \mathrm{~kg}$ de potássio $\left(\mathrm{K}_{2} \mathrm{O}\right)$ por hectare. Após a emergência, foi realizado um desbaste (estádio fenológico de cinco folhas), objetivando assegurar o estande de cinco plantas por metro linear, perfazendo uma população de 59.000 plantas por hectare na colheita. Foram realizadas duas adubações de cobertura: a primeira quando as plantas apresentaram quatro folhas $(60 \mathrm{~kg}$ de $\mathrm{N}$ e $30 \mathrm{~kg}$ de $\mathrm{K}_{2} \mathrm{O} \mathrm{ha}^{-1}$ ) e a segunda quando elas apresentaram oito folhas (30 kg de $\mathrm{N} \mathrm{ha}^{-1}$ ). A cultura foi instalada sob irrigação por aspersão do tipo pivô central. Foi feito o acompanhamento diário, com o objetivo de evitar danos decorrentes da lagarta-do-cartucho (Spodoptera frugiperda).

Os herbicidas avaliados no presente experimento foram atrazine + metolachlor, atrazine + óleo vegetal, atrazine + simazine e nicosulfuron, pois representam os principais produtos empregados na cultura de milho no Brasil. O herbicida atrazine + metolachlor foi aplicado em condições de pré-emergência da cultura e os demais em pós-emergência, quando a cultura estava com duas, quatro ou oito folhas (Tabela 1).

A aplicação dos herbicidas foi feita com auxílio de pulverizador costal, com pressão constante de $3,0 \mathrm{kgf} \mathrm{cm}^{-2}$, pressurizado com $\mathrm{CO}_{2}$, munido de barra com quatro bicos em leque, espaçados de $0,50 \mathrm{~m}$, com ângulo de $80^{\circ}$, e dose correspondente a $300 \mathrm{~L} \mathrm{ha}^{-1} \mathrm{de}$ calda. Todas as parcelas do experimento foram mantidas livres da competição de plantas daninhas por meio de capinas manuais, durante o ciclo da cultura, objetivando evitar a interferência das plantas daninhas. Foi observado o intervalo de sete dias entre as adubações de cobertura nitrogenada e a aplicação do herbicida nicosulfuron e evitou-se a aplicação de inseticidas organofosforados para controle da lagarta-do-cartucho. O delineamento experimental adotado foi o de blocos ao acaso, apresentando 22 tratamentos e três repetições. Cada parcela experimental era constituída de quatro linhas, espaçadas de $0,85 \mathrm{~m}, \operatorname{com} 6,0 \mathrm{~m}$ de comprimento. As linhas externas foram consideradas como bordadura. Aos resultados obtidos foi aplicado o teste F, para verificar se havia diferenças estatisticamente significativas entre os tratamentos; as médias foram comparadas pelo teste de Tukey a $5 \%$ de probabilidade.

Os caracteres agronômicos avaliados foram: fenologia da cultura de milho, avaliada diariamente, utilizando a escala proposta por Fancelli (1986) e Fancelli \& Dourado-Neto (1997a); sintomas visuais de fitotoxicidade, aos 7, 14 e 21 dias após aplicação dos herbicidas, adotando-se a escala de notas de 1 a 9, proposta pela EWRC (1964); comprimento de 20 espigas; número de fileiras por espiga e número de grãos por fileira; massa de 1.000 grãos (corrigidos para 14\% de umidade) obtidos a partir de oito amostras de 100 grãos ao acaso; e rendimento de grãos corrigidos para $14 \%$ de umidade.

\section{RESULTADOS E DISCUSSÃO}

Foi observado que a aplicação de herbicidas, em diferentes estádios fenológicos da cultura de milho, não afetou a duração normal desses estádios, principalmente daqueles que definem o rendimento final da cultura de milho (estádios correspondentes a 4, 8 e 12 folhas e grão leitoso). A duração desses estádios depende, principalmente, das condições climáticas (temperatura), das características do híbrido de milho e de algumas práticas agronômicas, como irrigação e adubação, sendo também alterada pelas práticas agrícolas.

As notas relativas aos sintomas visuais de fitotoxicidade causados na cultura de milho dos tratamentos que continham a mistura de (atrazine + metolachlor) + nicosulfuron $\left[(1.000+1.500)+20\right.$ g i.a. ha $\left.{ }^{-1}\right]$, quando aplicados no estádio de duas folhas definitivas, nicosulfuron (52 g i.a. ha ${ }^{-1}$ ) e (atrazine + óleo vegetal $)+$ nicosulfuron $[(800+600)+$ 
52 g i.a. ha ${ }^{-1}$, quando aplicados na cultura com quatro e oito folhas definitivas, indicaram efeitos muito leves de fitotoxicidade (nota 2 na escala do EWRC). Os sintomas visuais foram manchas estriadas de clorose, acompanhando as nervuras. Para a mistura (atrazine + metolachlor $)+$ nicosulfuron $[(1.000+1.500)+$ 20 g i.a. ha ${ }^{-1}$, os sintomas de fitotoxicidade foram observados aos sete dias, desaparecendo naturalmente aos 14 dias após a aplicação dos herbicidas. Nos tratamentos com a aplicação de nicosulfuron (40 g i.a. ha ${ }^{-1}$ ) e (atrazine + óleo vegetal $)+$ nicosulfuron $[(800+600)+$ 52 g i.a. ha ${ }^{-1}$, os sintomas de fitotoxicidade foram observados aos três dias depois da aplicação, e aos sete dias após a aplicação as plantas haviam se recuperado desses sintomas integralmente. Resultados semelhantes foram observados por Vicente \& Sawada (1997), que aplicaram nicosulfuron a $120 \mathrm{~g} \mathrm{ha}^{-1}$ na variedade de milho OCEPAR 720 no estádio fenológico de sete a oito folhas definitivas; estes autores também encontraram sintomas iniciais de fitotoxicidade leves logo após a aplicação do herbicida, porém as plantas recuperaram-se integralmente.

Os resultados de comprimento da espiga (Tabela 2) mostram que a aplicação de herbicidas em diferentes estádios fenológicos da cultura de milho não afetou estatisticamente este parâmetro avaliado.

Pode-se observar, na Tabela 2, que a aplicação de herbicidas nos diferentes estádios fenológicos afetou significativamente o número de fileiras de milho por espiga. Os tratamentos testemunha e atrazine + simazine $(\mathrm{NF}=4)$ foram estatisticamente diferentes dos tratamentos com nicosulfuron $\left(40\right.$ e 52 i.a. ha ${ }^{-1}-$ $\mathrm{NF}=8$ ) e (atrazine + óleo vegetal) + nicosulfuron $\left[(800+600) 40\right.$ g i.a. ha ${ }^{-1} ;(800+600)+$ 52 g i.a. ha-1 $-\mathrm{NF}=8$ ]. Aqueles tratamentos provocaram redução no número de fileiras

Tabela 1 - Tratamentos utilizados no experimento, descrevendo os herbicidas utilizados, as doses e o estádio fenológico da cultura no momento da aplicação dos herbicidas

\begin{tabular}{|c|c|c|c|c|c|}
\hline $\begin{array}{l}\text { Trata- } \\
\text { mento }\end{array}$ & Descrição & $\begin{array}{l}\text { P.C. }{ }^{5 /} \\
\left(\text { L ha }^{-1}\right)\end{array}$ & $\begin{array}{c}\text { i.a. }{ }^{6 /} \\
\left(\mathrm{g} \mathrm{ha}^{-1}\right)\end{array}$ & $\mathrm{NF}^{7 /}$ & $\mathrm{EF}^{\underline{8} /}$ \\
\hline 1 & Testemunha sem aplicação de herbicida & - & - & - & - \\
\hline 2 & atrazine + metolachlor ${ }^{1 / 1}$ & 7,0 & $1.400+2.100$ & 0 & - \\
\hline 3 & (atrazine + metolachlor) + nicosulfuron ${ }^{2}$ & $5,0+0,5$ & $(1.000+1.500)+20$ & 2 & $0-1$ \\
\hline 4 & atrazine + óleo vegeta $1^{\frac{3}{3}}$ & 6,0 & $2.400,0+1.800$ & 2 & $0-1$ \\
\hline 5 & atrazine + simazine $e^{4}$ & 5,0 & $1.250+1.250$ & 2 & $0-1$ \\
\hline 6 & nicosulfuron & 1,0 & 40 & 2 & $0-1$ \\
\hline 7 & nicosulfuron & 0,5 & 20 & 4 & 1 \\
\hline 8 & nicosulfuron & 1,0 & 40 & 4 & 1 \\
\hline 9 & nicosulfuron & 1,3 & 52 & 4 & 1 \\
\hline 10 & (atrazine + óleo vegetal) + nicosulfuron & $2,0+0,5$ & $(800+600)+20$ & 4 & 1 \\
\hline 11 & (atrazine + óleo vegetal) + nicosulfuron & $2,0+1,0$ & $(800+600)+40$ & 4 & 1 \\
\hline 12 & (atrazine + óleo vegetal) + nicosulfuron & $2,0+1,3$ & $(800+600)+52$ & 4 & 1 \\
\hline 13 & atrazine + óleo vegetal & 6,0 & $2.400,0+1.800$ & 4 & 1 \\
\hline 14 & atrazine + simazine & 5,0 & $1.250+1.250$ & 4 & 1 \\
\hline 15 & nicosulfuron & 0,5 & 20 & 8 & 2 \\
\hline 16 & nicosulfuron & 1,0 & 40 & 8 & 2 \\
\hline 17 & nicosulfuron & 1,3 & 52 & 8 & 2 \\
\hline 18 & (atrazine + óleo vegetal) + nicosulfuron & $2,0+0,5$ & $(800+600)+20$ & 8 & 2 \\
\hline 19 & (atrazine + óleo vegetal) + nicosulfuron & $2,0+1,0$ & $(800+600)+20$ & 8 & 2 \\
\hline 20 & (atrazine + óleo vegetal) + nicosulfuron & $2,0+1,3$ & $(800+600)+40$ & 8 & 2 \\
\hline 21 & atrazine + óleo vegetal & 6,0 & $(800+600)+52$ & 8 & 2 \\
\hline 22 & atrazine + simazine & 5,0 & $1.250+1.250$ & 8 & 2 \\
\hline
\end{tabular}

${ }^{1 /}$ Primestra SC $\left(200,0+300,0 \mathrm{~g} \mathrm{~L}^{-1}\right) ;{ }^{2 /}$ Sanson $\left(40,0 \mathrm{~g} \mathrm{~L}^{-1}\right) ;{ }^{3 /}$ Primóleo $\left(400,0+300,0 \mathrm{~g} \mathrm{~L}^{-1}\right) ;{ }^{4 /}$ Primatop SC $\left(250,0+250,0 \mathrm{~g} \mathrm{~L}{ }^{-1}\right) ;{ }^{5 /}$ P.C.: Produto comercial; ${ }^{6 /}$ i.a.: ingrediente ativo; ${ }^{7 /} \mathrm{NF}$ : número de folhas da cultura de milho no momento da aplicação dos tratamentos herbicidas; ${ }^{8 /} \mathrm{EF}$ : estádio fenológico da cultura de milho no momento da aplicação dos tratamentos herbicidas.

Observação - em todos os tratamentos foi feito o controle manual das plantas daninhas com o objetivo de evitar qualquer tipo de interferência destas plantas na cultura de milho. 
Tabela 2 - Resultados médios dos componentes de produção nos diferentes tratamentos

\begin{tabular}{|c|c|c|c|c|c|c|}
\hline \multirow{2}{*}{$\mathrm{T}^{\underline{1} /}$} & \multirow{2}{*}{ Descrição } & \multicolumn{5}{|c|}{ Médias* } \\
\hline & & $\mathrm{Ce}^{2 /}$ & $\mathrm{Nf}^{2 /}$ & $\mathrm{Gf}^{2 / 1}$ & $\mathrm{Mg}^{2 /}$ & $\mathrm{Rg}^{2 /}$ \\
\hline 1 & Testemunha & $16,36 \mathrm{a}$ & $14,66 \mathrm{a}$ & $35,82 \mathrm{a}$ & $312,90 \mathrm{ab}$ & $9.573,5 \mathrm{a}$ \\
\hline 2 & atrazine + metolachlor $\left(7,0 \mathrm{~L} \mathrm{ha}^{-1}\right)$ & $15,90 \mathrm{a}$ & $14,23 \mathrm{ab}$ & $34,53 \mathrm{ab}$ & $308,93 \mathrm{ab}$ & $8.877,4 \mathrm{abc}$ \\
\hline 3 & atrazine + metolachlor $\left(5,0 \mathrm{~L} \mathrm{ha}^{-1}\right)+$ nicosulfuron $\left(0,5 \mathrm{~L} \mathrm{ha}^{-1}\right)$ & $16,00 \mathrm{a}$ & $14,23 \mathrm{ab}$ & $32,95 \mathrm{ab}$ & "307,06ab & $8.583,3 \mathrm{abc}$ \\
\hline 4 & atrazine + óleo vegetal $\left(6,0 \mathrm{~L} \mathrm{ha}{ }^{-1}\right)$ & $15,19 \mathrm{a}$ & $14,26 \mathrm{ab}$ & $34,15 \mathrm{ab}$ & $308,83 \mathrm{ab}$ & 8.789,2abc \\
\hline 5 & atrazine + simazine $\left(5,0 \mathrm{~L} \mathrm{ha}^{-1}\right)$ & $16,27 \mathrm{a}$ & $14,03 \mathrm{ab}$ & $34,38 \mathrm{ab}$ & $306,44 a b$ & $8.652,0 \mathrm{abc}$ \\
\hline 6 & nicosulfuron $\left(1,0 \mathrm{~L} \mathrm{ha}^{-1}\right)$ & $15,94 \mathrm{a}$ & $14,17 \mathrm{ab}$ & $34,43 \mathrm{ab}$ & $313,09 \mathrm{ab}$ & $8.514,7 \mathrm{abc}$ \\
\hline 7 & nicosulfuron $\left(0,5 \mathrm{~L} \mathrm{ha}^{-1}\right)$ & $16,37 \mathrm{a}$ & $14,13 \mathrm{ab}$ & $34,50 \mathrm{ab}$ & $299,51 \mathrm{~b}$ & $8.931,4 \mathrm{abc}$ \\
\hline 8 & nicosulfuron $\left(1,0 \mathrm{~L} \mathrm{ha}^{-1}\right)$ & $16,09 \mathrm{a}$ & $14,36 \mathrm{ab}$ & $34,50 \mathrm{ab}$ & $309,96 a b$ & $8.725,5 \mathrm{abc}$ \\
\hline 9 & nicosulfuron $\left(1,3 \mathrm{~L} \mathrm{ha}^{-1}\right)$ & $15,98 \mathrm{a}$ & $14,30 \mathrm{ab}$ & $33,75 \mathrm{ab}$ & $311,60 \mathrm{ab}$ & $8.154,4 \mathrm{c}$ \\
\hline 10 & atrazine + óleo vegetal $\left(2,0 \mathrm{~L} \mathrm{ha}^{-1}\right)+$ nicosulfuron $\left(0,5 \mathrm{~L} \mathrm{ha}^{-1}\right)$ & $16,20 \mathrm{a}$ & $14,13 \mathrm{ab}$ & $34,25 \mathrm{ab}$ & $314,18 \mathrm{ab}$ & $9.426,5 \mathrm{ab}$ \\
\hline 11 & atrazine + óleo vegetal $\left(2,0 \mathrm{~L} \mathrm{ha}^{-1}\right)+$ nicosulfuron $\left(1,0 \mathrm{~L} \mathrm{ha}^{-1}\right)$ & $16,02 \mathrm{a}$ & $14,17 \mathrm{ab}$ & $34,63 \mathrm{ab}$ & "'304,54ab & $9.004,5 \mathrm{abc}$ \\
\hline 12 & atrazine + óleo vegetal $\left(2,0 \mathrm{~L} \mathrm{ha}^{-1}\right)+$ nicosulfuron $\left(1,3 \mathrm{~L} \mathrm{ha}^{-1}\right)$ & $16,00 \mathrm{a}$ & $14,23 \mathrm{ab}$ & $34,19 \mathrm{ab}$ & $301,18 \mathrm{~b}$ & $8.661,8 \mathrm{abc}$ \\
\hline 13 & atrazine + óleo vegetal $\left(6,0 \mathrm{~L} \mathrm{ha}^{-1}\right)$ & $16,09 \mathrm{a}$ & $14,10 \mathrm{ab}$ & $34,24 \mathrm{ab}$ & $310,74 \mathrm{ab}$ & $8.941,2 \mathrm{abc}$ \\
\hline 14 & atrazine + simazine $\left(5,0 \mathrm{~L} \mathrm{ha}^{-1}\right)$ & $16,04 \mathrm{a}$ & $14,53 \mathrm{a}$ & $34,23 \mathrm{ab}$ & $304,57 \mathrm{ab}$ & $8.921,6 \mathrm{abc}$ \\
\hline 15 & nicosulfuron $\left(0,5 \mathrm{~L} \mathrm{ha}^{-1}\right)$ & $16,03 \mathrm{a}$ & $14,10 \mathrm{ab}$ & $34,82 \mathrm{ab}$ & $315,70 \mathrm{ab}$ & $8.519,6 \mathrm{abc}$ \\
\hline 16 & nicosulfuron $\left(1,0 \mathrm{~L} \mathrm{ha}^{-1}\right)$ & $16,06 \mathrm{a}$ & $13,83 \mathrm{bc}$ & $34,25 \mathrm{ab}$ & $312,00 \mathrm{ab}$ & $8.661,8 \mathrm{abc}$ \\
\hline 17 & nicosulfuron $\left(1,3 \mathrm{~L} \mathrm{ha}^{-1}\right) \quad m$ & $15,84 \mathrm{a}$ & $13,37 \mathrm{c}$ & $33,88 \mathrm{ab}$ & $323,83 a$ & $8.411,8 \mathrm{abc}$ \\
\hline 18 & atrazine + óleo vegetal $\left(2,0 \mathrm{~L} \mathrm{ha}^{-1}\right)+$ nicosulfuron $\left(0,5 \mathrm{~L} \mathrm{ha}^{-1}\right)$ & $16,21 \mathrm{a}$ & $14,07 \mathrm{ab}$ & $33,53 \mathrm{ab}$ & $321,36 \mathrm{ab}$ & $8.500,0 \mathrm{abc}$ \\
\hline 19 & atrazine + óleo vegetal $\left(2,0 \mathrm{~L} \mathrm{ha}{ }^{-1}\right)+$ nicosulfuron $\left(1,0 \mathrm{~L} \mathrm{ha}^{-1}\right)$ & $16,13 \mathrm{a}$ & $13,73 b c$ & $33,03 \mathrm{ab}$ & $323,41 \mathrm{a}$ & $8.169,1 \mathrm{bc}$ \\
\hline 20 & atrazine + óleo vegetal $\left(2,0 \mathrm{~L} \mathrm{ha}^{-1}\right)+$ nicosulfuron $\left(1,3 \mathrm{~L} \mathrm{ha}^{-1}\right)$ & $15,84 \mathrm{a}$ & $13,76 \mathrm{bc}$ & $32,38 \mathrm{~b}$ & $325,18 \mathrm{a}$ & $7.882,4 \mathrm{c}$ \\
\hline 21 & atrazine + óleo vegetal $\left(6 \mathrm{~L} \mathrm{ha}^{-1}\right)$ & $15,79 \mathrm{a}$ & $14,37 \mathrm{ab}$ & $33,16 a b$ & $320,74 \mathrm{ab}$ & $8.328,4 \mathrm{abc}$ \\
\hline 22 & atrazine + simazine $\left(5,0 \mathrm{~L} \mathrm{ha}^{-1}\right)$ & $16,15 \mathrm{a}$ & $14,20 \mathrm{ab}$ & $33,91 \mathrm{ab}$ & $313,33 \mathrm{ab}$ & $8.627,4 \mathrm{abc}$ \\
\hline \multicolumn{2}{|c|}{ Coeficiente de Variação (CV \%) } & 3,84 & 1,45 & 2,89 & 2,28 & 4,66 \\
\hline
\end{tabular}

* Médias em uma mesma coluna da tabela, seguidas da mesma letra, não diferem estatisticamente entre si a 5\% de probabilidade pelo teste de Tukey.

1’ T: tratamento e ${ }^{2 /} \mathrm{P}$ : prolificidade; Ce: comprimento da espiga $(\mathrm{cm})$; Nf: número de fileira de grão de milho por espiga; Gf: número de grãos de milho por fileira da espiga; $\mathrm{Mg}$ : massa de 1.000 grãos de milho (g); Rg: rendimento de grãos de milho (em $\mathrm{kg} \mathrm{ha}^{-1}$ ).

quando aplicados na cultura que apresentava oito folhas definitivas. Resultados semelhantes foram encontrados por Fancelli et al. (1998) os autores explicam que, quando as plantas de milho apresentam de quatro a seis folhas definitivas plenamente expandidas, o meristema apical finaliza sua fase vegetativa e inicia o processo de diferenciação dos primórdios da panícula. Após o início da diferenciação da panícula, quando a planta se encontra com sete a nove folhas definitivas plenamente expandidas, começa o processo de diferenciação floral da gema, que dará origem à espiga; logo após essa diferenciação, rapidamente, a planta determina o número de fileiras por espiga e o número de grãos por fileira que comporão a futura espiga (Andrade et al., 1996).

Para o número de grãos por fileira na espiga (Tabela 2), observa-se que a testemunha sem herbicida foi estatisticamente diferente do tratamento (atrazine + óleo vegetal) + nicosulfuron $[(800+600)-\mathrm{NF}=8]$. Os resultados da massa de 1.000 grãos (Tabela 2) apresentaram diferença estatisticamente significativa entre os tratamentos, provocada pela aplicação de herbicidas em diferentes estádios fenológicos da cultura. Os tratamentos nicosulfuron (52 g i.a. ha ${ }^{-1}-\mathrm{NF}=8$ ), (atrazine + óleo vegetal $)+$ nicosulfuron $[(800+600)+$ 40 g i.a. ha ${ }^{-1}$ e $(800+600)+52$ g i.a. ha ${ }^{-1}-\mathrm{NF}$ $=8$ ] foram estatisticamente diferentes dos tratamentos nicosulfuron $\left(20\right.$ g i.a. ha ${ }^{-1}-\mathrm{NF}=$ 4) e (atrazine + óleo vegetal) + nicosulfuron $\left[(800+600)+52\right.$ g i.a. ha $\left.{ }^{-1}-\mathrm{NF}=4\right)$. Aqueles tratamentos propiciaram aumento na massa de 1.000 grãos de milho (grãos mais densos), porém esse fato pode ser atribuído ao menor número de fileiras por espiga e ao menor número de grãos por fileira apresentados por esses tratamentos. Quando comparados com a testemunha, os tratamentos 17,19 e 20 apresentaram 3,3 a $3,9 \%$ de acréscimo na massa de 1.000 grãos, e os tratamentos 7 e 
12 , uma redução de 3,7 e $4,3 \%$, respectivamente. Andrade et al. (1996) evidenciaram que a diminuição de 70 a $80 \%$ do número de grãos proporcionou $30 \%$ de aumento de massa nos grãos remanescentes, demonstrando que o milho não apresenta a capacidade de compensar a perda de grãos pelo incremento em massa.

A análise estatística do rendimento de grãos de milho (Tabela 2) demonstra que a testemunha foi estatisticamente superior aos tratamentos nicosulfuron (52 g i.a. ha ${ }^{-1}$, $\mathrm{NF}=4$ ) e (atrazine + óleo vegetal) + nicosulfuron $\left[(800+600)+40\right.$ g i.a. ha ${ }^{-1}$ e $((800+600)+$ 52 g i.a. ha- ${ }^{-1}, \mathrm{NF}=8$ ], os que apresentaram os menores valores. A maior média foi apresentada pelo tratamento testemunha sem herbicida. Também, pode-se observar que os tratamentos em que o herbicida nicosulfuron fazia parte na dosagem de 52 g i.a. ha ${ }^{-1}$, aplicado nos estádios de quatro e oito folhas, provocaram redução do rendimento de grãos. Essa redução foi maior quando os herbicidas foram aplicados com as plantas de milho com oito folhas definitivas, principalmente por provocarem redução do número de fileiras por espiga e número de grãos por fileira. É importante ressaltar que a massa de 1.000 grãos foi maior nos tratamentos cujo herbicida foi aplicado no estádio de oito folhas das plantas, porém esse acréscimo no peso dos grãos não foi suficiente para compensar as reduções do número de grãos por espiga. A redução de rendimento de grãos dos tratamentos que apresentaram as menores médias em relação à testemunha foi entre 11,2 e 17,6\%, aproximadamente. Segundo Fancelli \& Dourado-Neto (1997b), o número de grãos por unidade de área constitui-se num dos mais importantes componentes determinantes do rendimento, o qual é influenciado por eventos ocorridos entre a emissão da quarta e décima folha definitiva da planta, além daqueles evidenciados no florescimento (fecundação). Buzatti (2000), na safra $97 / 98$, utilizando nicosulfuron nas doses de 0,0; 0,5; 0,75; e 1,0 L ha ${ }^{-1}$ no híbrido de milho P3063, no estádio até seis folhas expandidas, não observou redução do rendimento. No entanto, quando a aplicação foi realizada a partir da sétima folha expandida, foi constatada redução do rendimento de grão.

Como conclusões gerais do experimento, pode ser ressaltado que a duração dos estádios fenológicos das plantas de milho não é afetada pelos herbicidas e doses utilizados em qualquer das épocas de aplicação efetuadas. Alguns tratamentos herbicidas afetam o rendimento de grãos da cultura de milho, sendo ele decorrente de alterações em alguns dos componentes de produção: (a) número de fileiras por espiga, (b) número de grãos por fileira e (c) massa de 1.000 grãos. O herbicida nicosulfuron, quando aplicado na dose de $52 \mathrm{~g}$ i.a. ha ${ }^{-1}$, sobre as plantas de milho no estádio fenológico de oito folhas definitivas, reduz o rendimento da cultura. A aplicação de herbicidas na cultura de milho deve ser efetuada até o estádio fenológico de quatro folhas (estádio fenológico 1), para evitar danos ao rendimento da cultura causados pela fitotoxicidade provocada por alguns herbicidas.

\section{LITERATURA CITADA}

ANDRADE, F. et al. Ecofisiologia del cultivo de maíz. Balcarce, La Barrosa, 1996. 292 p.

BUZATTI, W. J. S. Seletividade dos híbridos de milho aos herbicidas. Inf. Fundação ABC, 2, n. 8, 2000. p. 8-10.

CHRISTOFFOLETI, P. J.; MENDONÇA, C. G. Controle de plantas daninhas na cultura de milho: Enfoque atual. In: FANCELLI, A.L.; DOURADO-NETO, D. (Coords.). Milho: tecnologia e produtividade. Piracicaba: ESALQ, 2001. p. 60-95.

DOURADO-NETO, D.; FANCELLI, A. L. Milho: equações gerais para manejo da cultura de milho. In: FANCELLI, A.L.; DOURADO-NETO, D. (Coords.) Tecnologia da produção de milho. Piracicaba: Publique, 1997. p. 171-174.

EMBRAPA. Centro Nacional de Pesquisa de Solos. Sistema brasileiro de classificação de solos. Brasília: 1999. $412 \mathrm{p}$.

EUROPEAN WEED RESEARCH COUNCIL -EWRC. Committee of Methods in Weed Research. Oxford: 1964. v. 4, p. 88. (Report of the 3 and 4 Meetings).

FANCELLI, A. L. Plantas alimentícias: guia para aula, estudos e discussão. Piracicaba: ESALQ, 1986. 131 p.

FANCELLI, A. L.; DOURADO-NETO, D. Fenologia do milho. In: FANCELLI, A.L.; DOURADO-NETO, D. (Coords.). Tecnologia da produção de milho. Piracicaba: Publique, 1997a. p. 131-140.

FANCELLI, A. L.; DOURADO-NETO, D. Milho: ecofisiologia e rendimento. In: FANCELLI, A.L.; DOURADO-NETO, D. (Coords.). Tecnologia da produção de milho. Piracicaba: Publique, 1997b. p. 157-170.

FANCELLI, A. L.; DOURADO-NETO, D. Produção de milho. Guaíba: Agropecuária, 2000. 360 p. 
FANCELLI, A. L. et al. Influência do uso de herbicidas no rendimento e nos componentes de produção de milho. In: CONGRESSO NACIONAL DE MILHO E SORGO, 22., 1998, Recife. Resumos... Recife: 1998. p. 245.

FERREIRA, F. A.; SILVA, A. A. D. A.; FERREIRA, L. R. Efeitos do nicosulfuron, em duas formulações, sobre o controle de plantas daninhas na cultura do milho. In: CONGRESSO BRASILEIRO DA CIÊNCIA DAS PLANTAS DANINHAS, 19., 1995, Florianópolis. Resumos... Florianópolis, SBCPD, 1995. p. 164-165.

PINTO, J. J. O.; ALMEIDA, R.; HASSMANN, J. S. Avaliação do herbicida nicosulfuron aplicado em pósemergência na cultura de milho. In: CONGRESSO BRASILEIRO DE HERBICIDAS E PLANTAS

DANINHAS, 19., 1993, Londrina. Resumos... Londrina: IAPAR, 1993. p. 152.
SILVA, A. A.; ALTOÉ, I. F. Efeitos do nicosulfuron sobre a cultura do milho e no controle de plantas daninhas. In: CONGRESSO BRASILEIRO DE HERBICIDAS E PLANTAS DANINHAS, 19., 1993, Londrina. Resumos... Londrina: IAPAR, 1993. p. 153.

SILVA, A. A.; MELHORANÇA, A. L. Controle de plantas daninhas na cultura do milho. In: Empresa Brasileira de Pesquisa Agropecuária. UEPAE - Dourados, MS. Milho: informações técnicas. Dourados, 1991. p. 114-127. Dourados (Circular Técnica, 20).

VICENTE, D.; SAWADA, E. M. Efeitos de herbicidas aplicados em pós-emergência no controle de plantas daninhas e seletividade no milho (Zea mays), híbrido duplo Ocepar 720. In: CONGRESSO BRASILEIRO DA CIÊNCIA DAS PLANTAS DANINHAS, 21., 1997, Viçosa. Resumos... Viçosa, MG: SBCPD, 1997. p. 229. 